\title{
Modified Degrees of Streptomycin Dependence and Resistance in Escherichia coli
}

\author{
By G. E. PLUNKETT \\ Biochemical Research Foundation, Newark, Delaware, U.S.A.
}

(Received 25 June 1964)

\section{SUMMARY}

For three streptomycin-dependent (S-dependent) strains of Escherichia coli, the streptomycin concentration necessary for optimal growth during incubation for $24 \mathrm{hr}$ in a nutrient broth medium was about $10 \mu \mathrm{g}$. $/ \mathrm{ml}$. Less than $5 \mu \mathrm{g} . / \mathrm{ml}$. was sufficient for fairly heavy growth and the minimal streptomycin concentration permitting appreciable growth was $0 \cdot 40 \mu \mathrm{g} . / \mathrm{ml}$. Division of S-dependent bacteria was inhibited at streptomycin concentrations greater than $20 \mu \mathrm{g} . / \mathrm{ml}$. and small inocula gave no visible growth in $24 \mathrm{hr}$ at more than $30 \mu \mathrm{g}$. streptomycin $/ \mathrm{ml}$.

Following addition of any of several salts to the growth medium at $0.05 \mathrm{M}$ growth occurred over a wide range of streptomycin concentrations and the optimum was increased from twofold to as much as 1000-fold. Maximal concentration of streptomycin in which growth of S-dependent Escherichia coli was possible increased to as high as $20,000 \mu \mathrm{g}$. streptomycin $/ \mathrm{ml}$. in some instances, and the minimal concentration which supported growth was increased in the presence of several of the salts. Salts also increased the degree of resistance of a streptomycin-resistant $\boldsymbol{E}$. coli mutant from 20 to as much as $10,000 \mu \mathrm{g}$. streptomycin $/ \mathrm{ml}$. In $0 \cdot 10 \mathrm{M}$ phosphate-buffered nutrient broth, maximal and optimal concentrations of streptomycin increased with increasing acidity; at pH 5.8 heavy growth of an S-dependent strain of $E$. coli occurred at $200,000 \mu \mathrm{g}$. streptomycin $/ \mathrm{ml}$.

\section{INTRODUCTION}

Growth rates of streptomycin-dependent (S-dependent) bacteria in a mineral medium are proportional to streptomycin concentration (Spotts, 1962) and fairly high streptomycin concentrations, $100 \mu \mathrm{g}$. or more $/ \mathrm{ml}$., have commonly been used to obtain optimal growth. The activity of streptomycin as an antibiotic is markedly decreased in the presence of salts or in salt-containing defined media however (see Henry \& Hobby, 1949; Wasserman, Lessner \& West, 1954), and its function as a growth factor for dependent strains may be subject to the same salt effect (Engelberg $\&$ Artman, 1962). The 'true' streptomycin optimum for such strains may then be well below reported values. The amount of streptomycin necessary for growth has, in fact, been found to vary with the culture medium (Hashimoto, 1959; Goldschmidt, Matney \& Bausum, 1962). We had noted that several S-dependent strains of Escherichia coli, routinely grown in nutrient broth at rather low streptomycin concentrations, grew well in the chemically defined minimal medium of Davis \& Mingioli (1950) only at concentrations of streptomycin up to 100 times as high. We have therefore attempted to define the optimal streptomycin concentration, as well as the minimal and maximal values for growth of three S-dependent 
strains of $E$. coli in an ordinary nutrient medium, and to determine the extent to which these values can be modified by individual salts. Also some study has been made of the influence of salts on the degree of resistance of a low-level streptomycin-resistant mutant.

\section{METHODS}

Bacterial strains. Three S-dependent strains of Escherichia coli were used: Sd-4 was originally obtained from Dr M. Demerec and has been maintained here as a stock culture for several years; strains $\mathrm{HB}$ and D-R (Funk \& Plunkett, 1960; Plunkett, 1962) were isolated in this laboratory. The resistant strain, SR, was derived here from $E$. coli strain ATCC 11887.

Media. Difco Nutrient Broth, free of added salt, was the basal growth medium; nutrient agar was used for plating. For studying salt effects the broth was made up in $0.05 \mathrm{M}$-salt solutions before sterilization. Streptomycin sulphate was added to the medium to give the desired concentrations just before use.

Cultural conditions. S-dependent bacteria for the initial inoculum in each experiment were grown overnight at $37.5^{\circ}$ in nutrient broth containing $10 \mu \mathrm{g}$. streptomycin $/ \mathrm{ml}$., resistant bacteria in nutrient broth alone. Samples $(5 \mathrm{ml}$.) of the various growth media which contained graded concentrations of streptomycin were then inoculated with $2 \times 10^{3}$ to $5 \times 10^{3}$ bacteria of either the S-dependent or Sresistant type. The inoculated cultures, in small flasks, were shaken at $37 \cdot 5^{\circ}$ for $24 \mathrm{hr}$. The extent of growth in each flask was then determined in terms of light extinction (E) readings at $650 \mathrm{~m} \mu$, with uninoculated medium as a reference. For a few experiments larger starting inocula, $10^{4}$ to $10^{5}$ bacteria taken directly from stock cultures, were used. For determining their response to streptomycin on a solid medium, bacteria were spread on series of nutrient agar plates containing different concentrations of streptomycin. Degrees of resistance or dependence were judged by the time at which colonies first became visible, by comparative counts, and by the final size and overall appearance of the colonies on continued incubation.

\section{RESULTS}

\section{Optimal, maximal and minimal streptomycin concentrations for growth}

In salt-free nutrient broth at streptomycin concentrations increasing in $5 \mu \mathrm{g} . / \mathrm{ml}$. increments from 0 to $60 \mu \mathrm{g}$. $/ \mathrm{ml}$., turbidity at the end of $24 \mathrm{hr}$ was highest at $10 \mu \mathrm{g} . / \mathrm{ml}$. There was, however, nearly equivalent growth at 5 and also at 15 and $20 \mu \mathrm{g} . / \mathrm{ml}$. for strains HB and D-R, and for Sd-4 at 5 and $15 \mu \mathrm{g} . / \mathrm{ml}$. At concentrations higher than $25 \mu \mathrm{g} . / \mathrm{ml}$. extinction readings declined rapidly and there was little or no visible turbidity in $24 \mathrm{hr}$ at streptomycin concentrations above $30 \mu \mathrm{g} . / \mathrm{ml}$. When cultures at higher streptomycin concentrations were incubated for an additional $48 \mathrm{hr}$ growth became evident up to $100 \mu \mathrm{g}$. $/ \mathrm{ml}$., but rarely at concentrations greater than $150 \mu \mathrm{g} . / \mathrm{ml}$. The lowest tested streptomycin concentration that would support appreciable growth in nutrient broth was $0 \cdot 40 \mu \mathrm{g} . / \mathrm{ml}$. for all three S-dependent strains. Above this concentration the growth response improved rapidly and 2 or $3 \mu \mathrm{g} . / \mathrm{ml}$. were sufficient to produce heavily turbid cultures. Strain SR possessed only a slight resistance to streptomycin; the maximal streptomycin concentration which permitted visible growth in nutrient broth in $24 \mathrm{hr}$ was $20 \mu \mathrm{g} . / \mathrm{ml}$.; on further incubation to $72 \mathrm{hr}$ growth occurred up to 40 but seldom above $50 \mu \mathrm{g} . / \mathrm{ml}$. 
On solid media, optimal and maximal streptomycin concentrations were considerably higher than in broth. As judged by the time colonies first became visible on the plates and by their final size, the optimal streptomycin concentration for the S-dependent strains on nutrient agar was 50-100 $\mu \mathrm{g} . / \mathrm{ml}$. Outside of this range, rate of growth and overall size of the colonies were diminished. This was true regardless of the concentration of streptomycin in the broth in which the bacteria had been grown originally. S-dependent bacteria which grew well in nutrient broth at the optimal concentration, $10 \mu \mathrm{g}$. streptomycin $/ \mathrm{ml}$, gave only barely visible colonies in $24 \mathrm{hr}$ on $10 \mu \mathrm{g}$. streptomycin $/ \mathrm{ml}$. agar while, at the same time, large and clearly distinct colonies appeared on agar containing 50-100 $\mu \mathrm{g}$. streptomycin $/ \mathrm{ml}$. On continued incubation colonies appeared on agar up to $700 \mu \mathrm{g}$. streptomycin $/ \mathrm{ml}$. Similarly, the resistance of strain SR was higher on agar than in broth, with some colony growth becoming visible at streptomycin levels up to $400 \mu \mathrm{g} . / \mathrm{ml}$.

\section{Effect of salts}

Table 1 gives minimal, maximal, and optimal streptomycin concentrations for growth of S-dependent Escherichia coli as well as maximal concentrations for the resistant strain (SR) in salt-containing nutrient broth, when streptomycin was present at concentrations between 0 and $20,000 \mu \mathrm{g} . / \mathrm{ml}$. All the salts tested increased the maximal streptomycin concentration which permitted appreciable growth of S-dependent and S-resistant strains; the minimal requirement for S-dependent growth was also increased in several instances. The streptomycin concentration at which the heaviest growth of S-dependent bacteria took place was, in every case, increased. In many of these instances growth was almost equally heavy over a wide range of streptomycin concentrations; this is shown in Fig. 1, which gives specific data for the growth of strain $\mathrm{HB}$ in nutrient broth in comparison with growth in media containing each of four of the tested salts. Most salts had the additional effect of stimulating overall growth so that extinction readings at the optimal streptomycin concentrations in the salt-containing media were generally higher than those in nutrient broth controls at the $10 \mu \mathrm{g} . / \mathrm{ml}$. optimum for this medium. Even where overall growth was inhibited, as with $\mathrm{K}_{2} \mathrm{HPO}_{4}$, the optimal and maximal streptomycin concentrations were again at values higher than those for nutrient broth alone.

\section{Effects of phosphate buffer}

Most of the salts had little effect on the $\mathrm{pH}$ value of the medium at the concentration used. Nutrient broth alone had $\mathrm{pH}$ values between $6 \cdot 8$ and $7 \cdot 0$; the saltcontaining broths ranged from $\mathrm{pH} 6 \cdot 5$ to $7 \cdot 3$ except for $\mathrm{K}_{2} \mathrm{HPO}_{4}$ with a value near pH 8.0. When optimal and maximal streptomycin concentrations were determined for nutrient broth media made up in $0 \cdot 10 \mathrm{M}$-phosphate buffer at three $\mathrm{pH}$ values, growth responses corresponding to those shown in Fig. 2 were obtained. The acidbuffered medium was especially effective in increasing growth at high streptomycin concentrations. In one experiment heavy growth of strain HB was observed in this medium even with streptomycin $200,000 \mu \mathrm{g} . / \mathrm{ml}$. At $\mathrm{pH} 5 \cdot 8$ and $7 \cdot 0$ there was no appreciable growth at streptomycin $10 \mu \mathrm{g} . / \mathrm{ml}$., the optimum for nutrient broth, or even at $50 \mu \mathrm{g} . / \mathrm{ml}$. Optimal growth occurred only at concentrations of the order of several hundred $\mu \mathrm{g} . / \mathrm{ml}$. In the alkaline medium growth of S-dependent bacteria, 


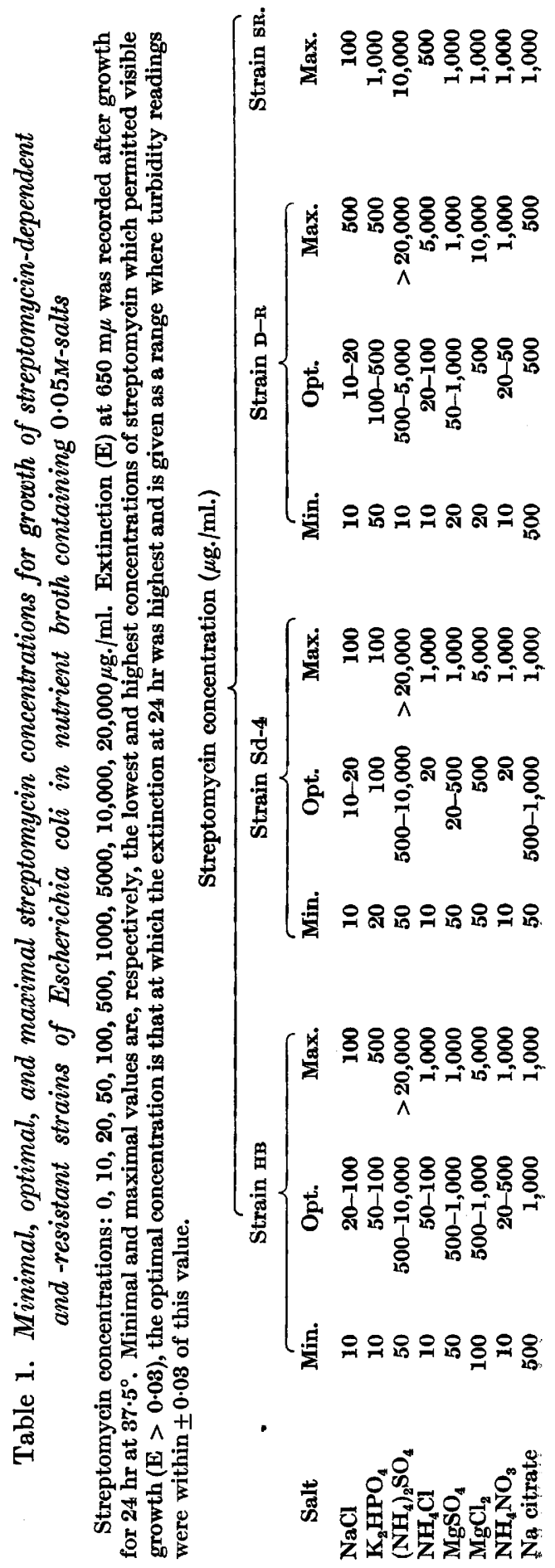


although limited, occurred again only at streptomycin concentrations well above those required for growth in plain nutrient broth. A phosphate-buffered medium also increased the degree of streptomycin resistance of strain sR. At pH 5.9 heavy growth of strain SR took place at all streptomycin concentrations to $24,000 \mu \mathrm{g} . / \mathrm{ml}$. At $\mathrm{pH} 7 \cdot 0$ resistance was increased to over 12,000 and at $\mathrm{pH} 7 \cdot 8$ to $3200 \mu \mathrm{g}$. strepto$\mathrm{mycin} / \mathrm{ml}$.

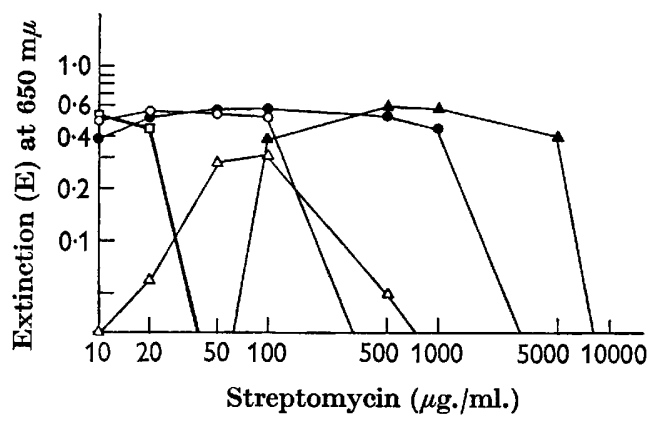

Fig. 1

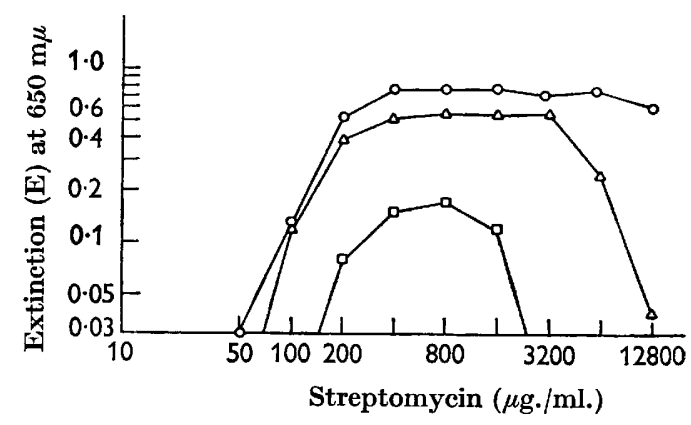

Fig. 2

Fig. 1. Effect of streptomycin concentration on growth of Escherichia coli strain HB in nutrient broth in the presence of $0.05 \mathrm{M}$-salts. $\square$, Nutrient broth control; $O, \mathrm{NaCl} ; \triangle$, $\mathrm{K}_{2} \mathrm{HPO}_{4} ; O, \mathrm{NH}_{4} \mathrm{Cl} ; \Delta, \mathrm{MgCl}_{2}$.

Fig. 2. Effect of streptomycin concentration on growth of Escherichia coli strain BB in phosphate-buffered nutrient broth. $O, \mathrm{pH} 5 \cdot 80 ; \triangle, \mathbf{p H ~ 7 \cdot 0 0 ;} \square, \mathrm{pH} 7 \cdot 75$.

\section{DISCUSSION}

The rather common practice of supplementing nutrient broth with $0.5 \% \mathrm{NaCl}$ may account for some of the high optimal streptomycin values that have been reported by others for streptomycin dependent growth in this medium. Our results indicate that, for three S-dependent strains of Escherichia coli, appreciable growth in ordinary nutrient broth was possible even at streptomycin $0 \cdot 40 \mu \mathrm{g} . / \mathrm{ml}$., and heavy growth at less than $5 \mu \mathrm{g} . / \mathrm{ml}$. In fact, in the absence of added salt, streptomycin actually inhibited the rate of growth of S-dependent bacteria at values only slightly in excess of the optimal $10 \mu \mathrm{g}$. $/ \mathrm{ml}$. This inhibition suggests that streptomycin retains some of its antibiotic action even when it is required for growth and it may give some support to the assumption that streptomycin functions at a site within the cell rather than its surface. It would be of interest in this respect to compare the effects of excess streptomycin on S-dependent bacteria, with those resulting from streptomycin treatment of sensitive bacteria, as a possible means of distinguishing primary from secondary streptomycin effects.

Engelberg \& Artman (1961) calculated that as little as 0.60 $\mu \mathrm{g}$. streptomycin $/ \mathrm{ml}$. medium should satisfy the requirement of Escherichia coli strain Sd-4, provided all the streptomycin was absorbed. Sodium chloride decreased streptomycin uptake however, and in a defined medium the amount of the antibiotic bound by the S-dependent bacteria was only a small fraction of that required for growth. It seems likely, therefore, that salt interference with streptomycin uptake may be in some part responsible for the highly elevated streptomycin requirements we have found in salt-containing media. However, the effect is of a greater magnitude than might be expected solely on the basis of competition for cell binding sites. The 
rather narrow range of effectiveness of streptomycin in nutrient broth alone and the inhibition of growth of S-dependent bacteria that occurred at a streptomycin concentration only 2.5 to 5 times the optimal value is in sharp contrast to the continued effectiveness of streptomycin as a growth factor over a wide range of concentrations, and up to values over 50 times the optimum in the presence of salts. Although the salt effect was a fairly general one, there was considerable variation in the effect of different salts even at equivalent ionic strengths. Specific ions are known to modify the activity of streptomycin against S-sensitive bacteria (Ørskov \& Ørskov, 1960; Hurwitz \& Rosano, 1958, 1962; Mager, Benedict \& Artman, 1962; Bragg \& Polglase, 1963; Willick \& Polglase, 1963) and similar effects might account in part for this variation. Magnesium, for example, is notably effective as a streptomycin antagonist. Since a function at the bacterial ribosome is postulated both for the magnesium ion (Hershko, Amoz \& Mager, 1961) and for streptomycin (Davies, 1964; Cox, White \& Flaks, 1964), competition for a binding site here could explain the high streptomycin requirement of S-dependent bacteria in the presence of magnesium salts. Other cations might be expected to have a similar effect.

This investigation was supported in part by a research grant (AI 05376-01) from the National Institute of Allergy and Infectious Diseases, U.S. Public Health Service.

\section{REFERENCES}

Bragg, P. D. \& Polglase, W. J. (1963). Action of dihydrostreptomycin and antagonism by cations. J. Bact. 85, 590 .

Cox, E. C., White, J. R. \& Flaks, J. G. (1964). Streptomycin action and the ribosome. Proc. nat. Acad. Sci., Wash. 51, 703.

Davres, J. E. (1964). Studies on the ribosomes of streptomycin-sensitive and resistant strains of Escherichia coli. Proc. nat. Acad. Sci., Wash. 51, 659.

Davis, B. D. \& Mingioli, E. S. (1950). Mutants of Escherichia coli requiring methionine or vitamin $B_{12}$. J. Bact. 60,17 .

Engelberg, H. \& Artman, M. (1961). Uptake of streptomycin by a streptomycin dependent mutant of Escherichia coli. Bull. Res. Coun. Israel, 9, 53.

Engelberg, H. \& Artman, M. (1962). Studies on streptomycin dependent bacteria: Uptake of ${ }^{14} \mathrm{C}$ streptomycin by a streptomycin dependent mutant of Escherichia coli. Biochim. biophys. Acta, 54, 533.

Funk, F. J. \& Plunketr, G. E. (1960). Bacterial culture suitable for antimutagen screening. Bact. Proc. p. 76.

Goloschmidt, E. P., Matney, T. S. \& Bausum, H. T. (1962). Genetic analysis of mutations from streptomycin dependence to independence in Salmonella typhimurium. Genetics, 47, 1475.

HASHIMOTO, K. (1959). Streptomycin resistance in Escherichia coli analyzed by transduction. Genetics, 45, 49.

HENRy, R. J. \& HobBy, G. L. (1949). The mode of action of streptomycin. In Streptomycin, p. 201. Ed. by S. A. Waksman. Baltimore: Williams and Wilkins Co.

Hershro, A., Amoz, S. \& MAGEr, J. (1961). Effect of polyamines and divalent metals on in vitro incorporation of amino acids into ribonucleoprotein particles. Biochem. biophys. Res. Commun. 5, 46.

Hurwitz, C. \& Rosano, C. L. (1958). Studies on mechanism of the streptomycin reaction. I. Phosphate reversal of the dihydrostreptomycin inactivation of Escherichia coli. J. Bact. 75, 1 i.

Hurwitz, C. \& Rosano, C. L. (1962). Chloramphenicol-sensitive and insensitive phases of the lethal action of streptomycin. J. Bact. 83, 1202. 
Mager, J., Benedict, M. \& Artman, M. (1962). A common site of action for polyamines and streptomycin. Biochim. biophys. Acta, 62, 202.

Ørskov, F. \& Ørskov, I. (1960). Sensitivity to dihydrostreptomycin of Enterobacteriaceae strains on media containing ammonium. Nature, Lond. 188, 75.

Plunketr, G. E. (1962). A temperature sensitive streptomycin requirement in an Escherichia coli mutant. J. Bact. 84, 275.

Spotrs, C. R. (1962). Physiological and biochemical studies on streptomycin dependence in Escherichia coli. J. gen. Microbiol. 28, 347.

Wasserman, A. E., Lessner, J. M. \& West, M. K. (1954). Reversal of the streptomycin injury of Escherichia coli. J. gen. Physiol. 38, 213.

Wilnick, G. E. \& Polgrase, W. J. (1963). Precipitation of Escherichia coli ribosomes with dihydrostreptomycin. J. Bact. 86, 352. 